\title{
The Role of Information and Communication Technology (ICT) in Iranian Olive Industrial Cluster
}

\author{
Azizi Jafar \\ Assistant Professor of Agricultural Economics \\ Department of Islamic Azad University, Rasht, Iran \\ E-mail: Jafar574@yahoo.com \\ T Aref Eshghi \\ Msc Graduate of Agricultural Management \\ Tabriz University, Tabriz, Iran \\ E-mail: ta_arefeshghi@yahoo.com
}

\begin{abstract}
The cluster development method is one of the successful developing methods in agricultural industries section and small industries, which is based on communication and creation cooperation network between cluster beneficiaries by increasing the social capital. In this research the data were collected by using census two stage survey from olive industrial units in mentioned geographical zone(North Iran) in 2007. The results of this research showed that the social capital in some of beneficiaries groups is weak and brittle, but because of their statements there is background of cooperation and increase of their social capital. After recognition and strengthening the effective factors on increase of social capital, can prepare the background for developing of new connective and informative technologies. Naturally economic discompetition of units, diseconomies of scale, negative competition in industry and the other problems which are investigated in the olive industrial cluster is resulting from the lack of information and connection between cluster actives. The aim of industrial cluster method is increasing the cooperation network between cluster members by increasing the communication and information which by increase in using information and communication technology will fallow social capital and then industrial cluster development method.
\end{abstract}

Keywords: Industrial cluster, Olive, Information and connections technology (ICT)

\section{Introduction}

Cluster development method was companioned with development of information and communication technology and believed that the development of economic activity is based on information interchange and communication between cluster members. In such economic perception, by increasing the social capital level the information and communication will be more important. In previous century human society accepted considerable effects from technology changes and ICT satisfied the communicative and informative needs which help to cause knowledge and make new possibilities for information interchange. Taking into consideration, the cluster development method is based on synergism, Information interchange, experiences and new scientific findings with economic perception causes important development of total cluster members which through this, ICT has a potential power to increase the human ability for creating new knowledge. Frank Webster in the book of informative society opinions says that the first definition of information that comes to mind is virtual definition. Significant information has one subject and it's containing is included a knowledge or an instruction about an object or a person. but Count Arow believes that briefly the definition of information is a decrease in risk and uncertainty. Information and knowledge is abled the manager to aware about weaknesses and threats of the industry and firm and to think about the cure and to have program about the powers and chances and to use this knowledge to connection, learning, meditation, decision and innovation in industrial unit. Based on Porter opinion, industrial cluster is a method in which there is a network of social and economic relations between units which have economic threats and common chances and this relation which formed by different communicative tools can change the competition of defeat-defeat for firms to competition of win-win by interchanging information. The development of information and communication technology will cause to create a bigger network companion with improvement of economic scale of unit in industrial cluster. In advanced countries, industrial units with 
making confidence could create a great change in small industries by using the information technology tools. Information and communication technology can create the great changes in total social and economic activities of cluster which is the most important modern entrepreneur tools in small industries. The aim of this study is to investigate the station of information and connection technology in forming and developing of industrial cluster and it's dynamic and also the effective factors in creating social capital which will cause to communication and information interchange.

\section{Methodology}

In this research the data were collected by completing the questionnaires and attendant interview with agents in olive oil extraction, processing and packing, soap making units and existing agent in market (the salers of olive products) in cluster geographical zone which is included small provinces Roodbar and Tarom. In this way at first the lists of total actives were prepared from the related organizations and then all of the existing units in the recorded statistics list were interviewed and the questionnaires were completed. The results were analyzed by the Spss program and in companion with recognizing the communicative and informative factors in cluster and the level use of communicative tools, the regression of the effective factors on communication and social capital were measured and then by using the linear regression method the impact multiplier were evaluated for the total of the cluster collection.

\section{Result and Discussion}

If can't know the Olive (Olea Europa) as an oldest plant witch is operated in the world, undoubtedly it should be known as one of the oldest plants of meditrane zone and specially middle east. According to the world statistics there are about 800 millions plant Olive trees in the area more than 10 million hectares in the world. The geographical limitation of the Olive industrial cluster is in the small provinces Roodbar in Guilan province and Tarom in Zanjan province. In cluster according to primary estimation of the recorded statistics, about 14804 persons are acting witch most of them are acting in the production section of olive crops means owning the groves. The remaining are acting in olive industries and their marketing and commerce which the investigated results is reported in under table. Because the olive oil extraction units (12 units), Olive processing units (250 units), filtration and packing units (15 units) and soap making units (7units) are formed the nucleus of cluster and main section of cluster, the rate of their connection and information interchange with each other, with after section which are the same input provider and production factors with his former section which formed the existing factors in market and commerce, and also with supporter structures and services supplier were investigated(Table1).

According to completing the questionnaires and accomplished interview with industrial cluster units which is included table olive processing units (250 units), oil extraction units (12 units), packing units (15 units) and traded units (250 units), is distinguished that there is a relation and proportional confidence between oil extraction units, processing and packing. These units have an active society which is named the society of Iranian olive oil and table olive that the boss of this society attends monthly in agricultural commission meeting of Islamic assembly and transfers the problems of society to the lawgivers of the country. In the other side, this society have a spread communication with the olive office of Agri-Jahad ministry which cause to service presentation of this office in relation with help money to units and solving the problems of the society. But this society couldn't make a good cooperation between units in common acquisition of inputs, crop sale, increasing the crop quality and their expert.

In interview section it is distinguished that units have an inclination in industrial cluster model and in explanated fields like the common acquisition of inputs, propaganda, marketing and etc, do the necessary cooperation. About the farmers, we should say that some production cooperative of olive farmer is organized but they are not active because of the executive problems. According to the interview with agents of these cooperative companies, it is distinguished that they have inclination in cooperation with oil extraction, processing and packing units and have inclination in activity in cluster model. Also during the interview with the protective organizations like Agri-Jahad ministry, standard office, the office of control on alimentary materials hygiene and agricultural bank, they expressed that although they have a week relation with industrial olive units but they have inclination to solve their problems with group cooperation. So according to this information can express that there is the potential of creation communication and suitable confidence in the cluster.

The signals of non confidence in the members of olive industrial cluster are:

a- Each one of the packing units in buying glass and the other vessels from preparation units of the other glass and vessels tries to stipulate in their contract that the making units of glass don't have the right to sale this glass to other packing units of olive in inside the country. 
b- Each of oil extraction and packing units by competition with each other tries to advance purchase their necessity inputs especially olive in higher prices which cause an increasing in olive price and pressure to smaller units that don't have turn over.

c- Between the farmers, don't exist an active society and most of them are pessimistic to each other and known the offer of formation of cooperative by each of farmers as a personal claims.

d- The level of confidence between farmer and oil extraction and packing units is not suitable too.

e- The competitive pricing condition of productions of each unit is competitive which is different in proportion to each other and when we ask about the pricing manner they don't mention any correct method and express the competition with other firms in which it is possible that the qualities be different.

f- There is no relation between the society of olive oil and salty olive with farmers and the other units.

The strength points and suitable potential for making confidence in olive industrial cluster:

a- The existence of one active society of oil extraction, production and packing units that named the society of olive oil and table olive of Iran which have a good relation with governmental organization and effort into the goals of units.

b- The potential of making garden owner cooperative and their direct relation with the society of olive oil of Iran which their relation could solve many problems of olive section such the debate of cost production and quality and etc.

So according to the existing condition, we can increase the amount of cooperation and confidence level because there are the necessary potential and proportional successes. The connective tools in cluster were:

1. The face to face relation between some units of the cluster with each other and the supporter structures.

2. Connection with some tools such telephone, mobile and fax.

In cluster there wasn't any electronic relation like website and email, poster, newspaper and etc in the cluster.

In the table 2, the concepts of mentioned numbers are:

0: The beneficiaries don't have any relation with together because they don't have any recognition about treats and common profits.

1: The beneficiaries have a connection with together which this connection is obligatory and their goal is based on necessity and providing the personal profit.

2: The beneficiaries, based on the existing short history have a positive relation with a tendency to cooperation in the direction of profits of total cluster.

3: The beneficiaries have an excellent relation with considerable effect on the total cluster.

According to the collected data, the amount of communication and the level of social capital are investigated by the variables like the knowledge and awareness level of managers of the units, the size of units, cash capital of units, the age of the managers of units, the amount of familiarity of units with electronic communicative tools like website and email.

The referring times to supporter structures like agri-Jahad ministry, industries organization and etc, the referring times to investigative centers and doing the team working in the formation mould and etc with the results are reported in the table3.

As the same as showed in the table3, there is a reverse relation between age and the confidence level rate and communication and it is significant at five percent level. In the other word the younger manager have a greater tendency to the relation and using the communicative tools to accessing the knowledge. The numbers of team working of individuals also showed a negative significant relation. The reason can be explained by the negative competition between the cluster beneficiaries which in practice confront their actions with the defeat-defeat law and so create a severe pessimism for them. The other factors were showed in the table have a positive and significant relation by the amount of tendency to the communication and social capital level. It means that whatever the managers of units have a lower age, higher education, more referring times to supporter structures and investigating centers and bigger size of units and more turn over they have a bigger tendency to communication and using the new communicative tools and so have a higher social capital level. Finally a simple line regression was estimated. In the model the confidence level and connection between the cluster members are as a dependent variable and the other variables which are reported in the top table are as independent variables which the results are in the table 4. 
According to the regressive results, it is recognized there isn't any relation between the referring times to investigative centers and communication and confidence level and there isn't any significant coefficient, but there is a significant relation between the other factors with the communication and confidence level which this relation with the numbers of team working is a reverse and negative relation and the other factors have a positive and significant relation. The total result of this research is the communication level between the cluster members form according to the confidence level or the governor social capital. Since the developing cluster method is creating the cooperation networks based on the confidence level so recognition of the effective factors on the confidence level and also the kinds of used tools in communication is very important. The investigations showed that the level of social capital in some of the beneficiaries group is week and brittle. But according to their statements, there is the cooperation field and increasing their social capital. After recognition and strengthening the effective factors on increasing the social capital can provide the field for developing the new communicative and informative technology. Naturally the non-competitive economic of units, diseconomies of size, negative competition in industry and the other investigated economic problems in olive industrial cluster is resulting from the informative and communicative poverty between the cluster actives. The goal of industrial cluster method is increasing the cooperation network between cluster members by increasing the communication and information. So according to the industrial cluster map which is showed in the below, informative communication and cooperation and confidence mould is showed. These relations sometimes are one way and sometimes are tow ways and the centers of information and services which are predicted in the map which elegant with the kind of working society can use the common communicative tools or the new advanced.

\section{References}

Azizi, J. (2007). The role of cluster development method in cooperation between university, Industrial and government. The conference of agricultural research in Islamic Azad university, Iran.

Arqette, T.J. (2002). Social discourse, scientific method and the digital divide: using information intelligence quotient. Dissertation. North western university.

Guoxiu, C. (2002). France and its agriculture: Advancing towards information utilization. Asian conference for information technology in agriculture, China.

Shaker, M.H.Z. (2006). A framework for developing and implementing effective information systems for agricultural research and development in Egypt. Proceedings of workshop rooting ICT in national agricultural research system. The Hague.

Table 1. The existing situation of olive industrial cluster in geographical zone (Roodbar and Tarom), 2007

\begin{tabular}{|c|c|c|}
\hline Row & title & Description \\
\hline 1 & Total population & 169775 person \\
\hline 2 & $\begin{array}{l}\text { The number of active operator in the olive } \\
\text { production section }\end{array}$ & 13500 garden owner \\
\hline 3 & $\begin{array}{l}\text { The number of employers in the Olive } \\
\text { section }\end{array}$ & 14804 person \\
\hline 4 & The olive cultured land & 16603 hectare \\
\hline 5 & The production rate of olive grain & $\begin{array}{c}30400 \text { tone of olive grain(6080 tone oil, } 24320 \text { tones } \\
\text { of productive olive) }\end{array}$ \\
\hline 6 & $\begin{array}{c}\text { The numbers of oil extraction } \\
\text { Units }\end{array}$ & $\begin{array}{c}12 \text { units with the capacity of } 25 \\
\text { tones/hour(11modern units, 1pressi units) }\end{array}$ \\
\hline 7 & $\begin{array}{l}\text { The numbers of green olive } \\
\text { processing units }\end{array}$ & 250 units \\
\hline 8 & The numbers of packing units & 15 units \\
\hline 9 & The numbers of soap making units & 7 units \\
\hline 10 & The numbers of local merchants & 250 units \\
\hline 11 & The numbers of olive oil exporter & 8 units \\
\hline 12 & Olive inquiries station & 2 center(center of Roodbar and center of Taram \\
\hline 13 & Olive brooder garden & 150 hectare \\
\hline
\end{tabular}

Origin: the information of olive plan office of agri. Jahad ministry and inquiry finding 
Table 2. Cooperation and confidence matrix in the level of olive industrial cluster

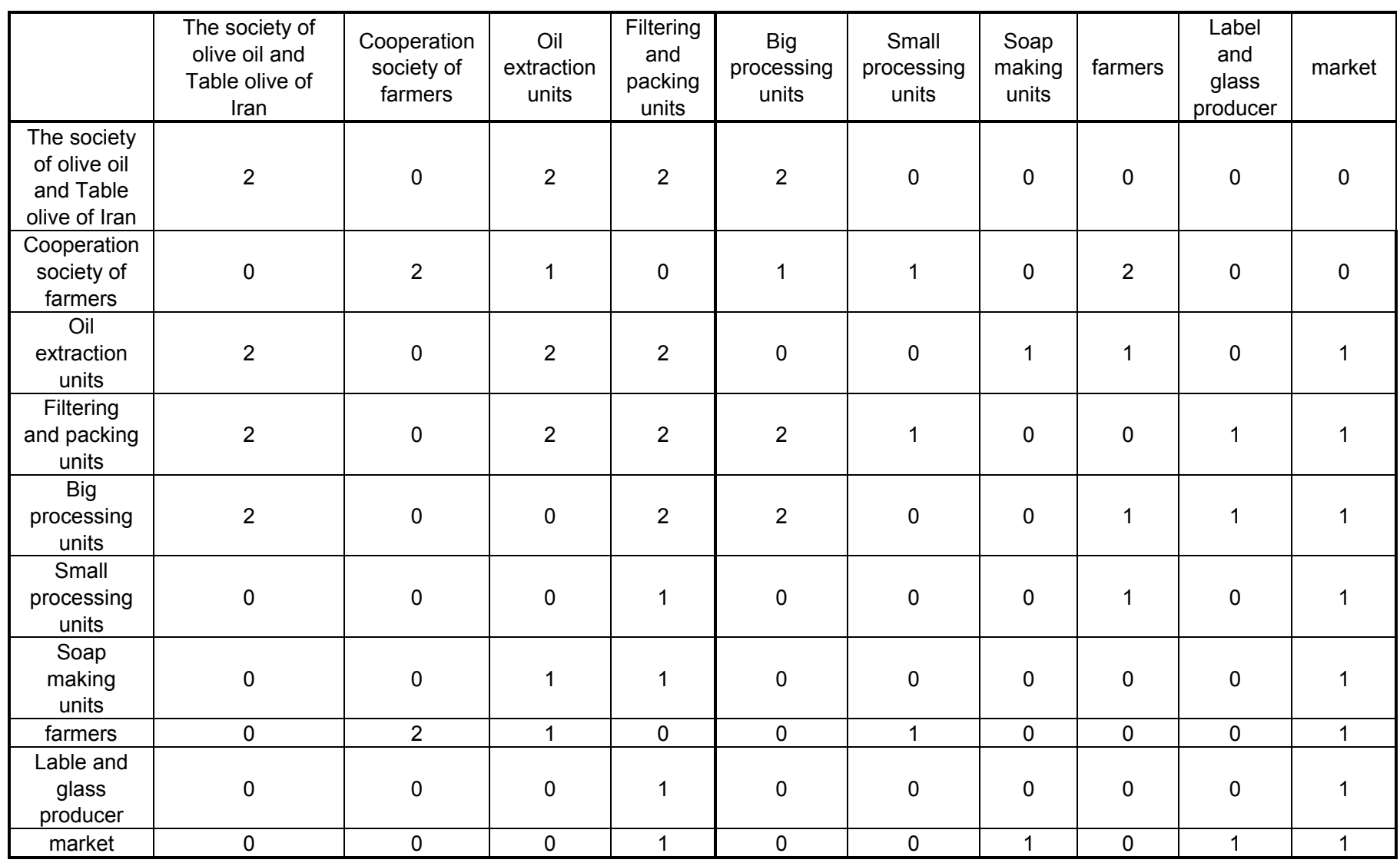

Origin: inquiry finding

Table 3. The correlation rate of recognized factors on the confidence level and the connection of industrial cluster activities

\begin{tabular}{|c|c|c|}
\hline Row & factor & The correlation rate (r) \\
\hline 1 & Education & $-0.648^{* *}$ \\
\hline 2 & Age & $0.423^{*}$ \\
\hline 3 & Familiarity rate with internet, .. & $0.733^{* *}$ \\
\hline 4 & The referring times to supporter structures & $0.600^{*}$ \\
\hline 5 & The referring times to investigative centers & $0.033^{* * *}$ \\
\hline 6 & The numbers of team workings & $-0.029^{*}$ \\
\hline 7 & Unit size (production volume) & $0.387^{* *}$ \\
\hline 8 & Turn over & $0.122^{*}$ \\
\hline
\end{tabular}

Origin: inquiry finding

Table 4. Regression coefficient of effective factors on confidence level and connection between the olive industrial cluster members

\begin{tabular}{|c|c|c|c|}
\hline Row & factor & coefficients & t-statistic \\
\hline 1 & Education & 0.6002 & $2.21^{* *}$ \\
\hline 2 & Age & -0.400 & $-3.02^{* * *}$ \\
\hline 3 & Familiarity rate with internet & 0.597 & $2.55^{* *}$ \\
\hline 4 & The referring times to supporter structure & 0.147 & $2.35^{* *}$ \\
\hline 5 & The referring times to investigative centers & 0.056 & 1.03 \\
\hline 6 & The numbers of team working & -0.009 & $2.02^{*}$ \\
\hline 7 & Unit size (production volume) & 0.014 & $2.72^{* *}$ \\
\hline 8 & Turn over & 0.391 & $4.90^{* * *}$ \\
\hline
\end{tabular}

Origin: inquiry finding 